
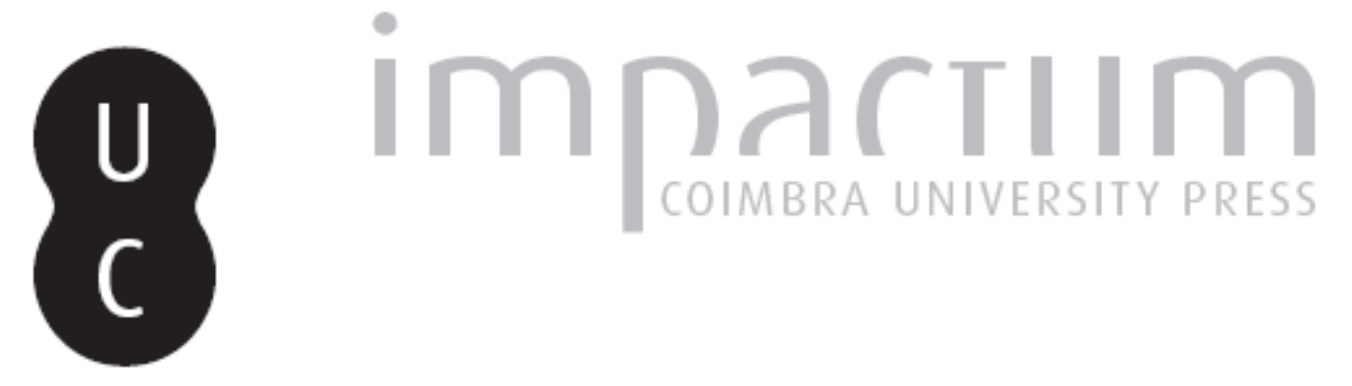

\title{
O discurso da história sobre a cidade, o paradigma e seus modelos
}

\section{Autor(es): $\quad$ Almeida, Maria João}

Publicado por: Imprensa da Universidade de Coimbra

URL persistente:

URI:http://hdl.handle.net/10316.2/42444

DOI:

DOI:https://doi.org/10.14195/0870-8584_0_1

Accessed : $\quad$ 26-Apr-2023 12:13:45

A navegação consulta e descarregamento dos títulos inseridos nas Bibliotecas Digitais UC Digitalis, UC Pombalina e UC Impactum, pressupõem a aceitação plena e sem reservas dos Termos e Condições de Uso destas Bibliotecas Digitais, disponíveis em https://digitalis.uc.pt/pt-pt/termos.

Conforme exposto nos referidos Termos e Condições de Uso, o descarregamento de títulos de acesso restrito requer uma licença válida de autorização devendo o utilizador aceder ao(s) documento(s) a partir de um endereço de IP da instituição detentora da supramencionada licença.

Ao utilizador é apenas permitido o descarregamento para uso pessoal, pelo que o emprego do(s) título(s) descarregado(s) para outro fim, designadamente comercial, carece de autorização do respetivo autor ou editor da obra.

Na medida em que todas as obras da UC Digitalis se encontram protegidas pelo Código do Direito de Autor e Direitos Conexos e demais legislação aplicável, toda a cópia, parcial ou total, deste documento, nos casos em que é legalmente admitida, deverá conter ou fazer-se acompanhar por este aviso.

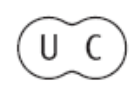




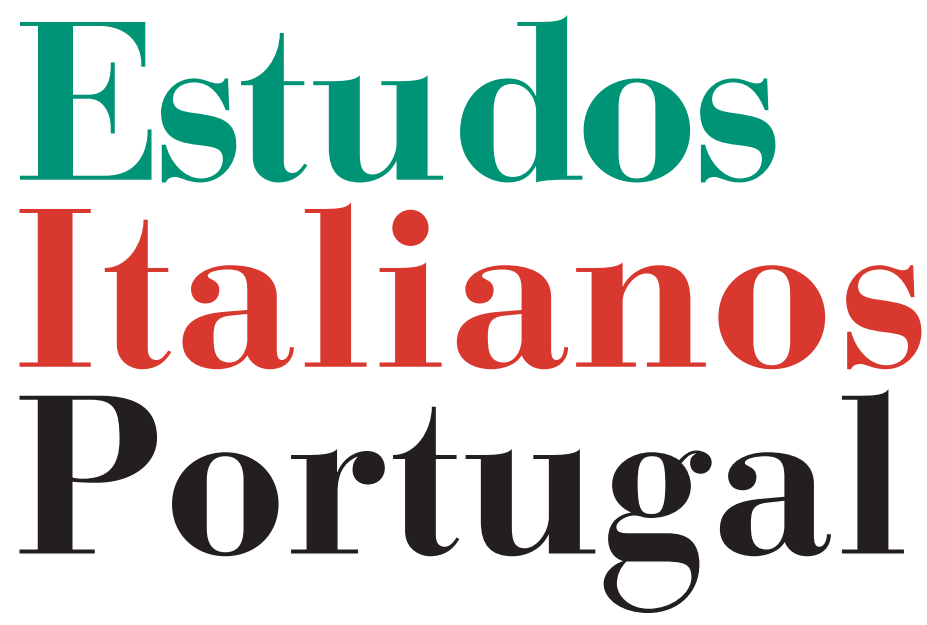

Instituto

Italiano

de Cultura

de Lisboa

Nova Série

$\mathrm{N}^{\mathbf{0}} \mathbf{0}$ 


\title{
O DISCURSO DA HISTÓRIA SOBRE A CIDADE, O PARADIGMA E SEUS MODELOS
}

\author{
Maria João Almeida
}

A escrita da história em Itália, na Baixa Idade Média, abundante e diversificada, tem na historiografia urbana um dos seus filões mais distintivos. Se este tipo de prática memorialista recorta a sua especificidade na qualidade de produto da grande estrutura política e social que é a cidade ${ }^{1}$, mais do que em qualquer outra área cultural europeia, foi na Itália das Comunas que encontrou as condições propícias para se afirmar.

Quando o autor anónimo senês de La sconfitta di Monte Aperto, um exemplar do registo da memória urbana do séc. XIII, em dado passo do texto anota "E tutti erano di buono volere e d'uno animo e d'una intenzione e bene disposti contra de' nostri inimici fiorentini [...]"2, demarca visivelmente o horizonte significativo da narrativa e o seu destinatário, uma obra da cidade e para a cidade. A forma possessiva "nostri" corresponde à declinação pessoal de um "nós" inclusivo que agrega ao "eu" (sujeito) um "vós" (destinatário), circunscrevendo assim o autor no interior de uma globalidade indistinta de outros indivíduos, todos unidos pelos laços de pertença a um colectivo no qual o "eu" se inclui por sinédoque como parte do conjunto. Por outro lado, no sintagma "nostri inimici fiorentini" fica também a descoberto, de acordo com a lógica que funda a qualidade de relação semântica inimigo/amigo e a específica designa- 
ção de uma entidade colectiva ("fiorentini"), o lugar de onde o autor fala. Posiciona-se no estatuto de membro de uma comunidade urbana, a sua ("amiga", em relação a outra, "inimiga"), que se identifica, pelos dados contextuais explícitos, com a população de Siena. Esta encontra-se subsumida no quantificador "tutti" afectado pela forma verbal da terceira pessoa do plural que verbaliza um "eles" de que o "eu" se diferencia estruturalmente, sujeito enunciador de um discurso testemunhal onde "eles" e os seus 'feitos' entram como objecto repertoriado pelo presente da escrita.

Este simples exercício sobre a estrutura discursiva do texto, explicitamente personalizada pela subjectividade de um "eu-nós”, escolhido entre tantos outros afins rastreáveis no corpus da historiografia urbana, permite elucidar, creio, os nexos de implicação entre a realidade citadina medieval das áreas setentrional e central da Península Itálica e a escrita da história citadina que nelas surgiu a partir do séc. XII. É sabido que nos centros urbanos da área geográfica acima referida, que conheceu um extraordinário crescimento económico após o ano mil, se instituiu no Reino de Itália, por volta dos finais do séc. XI, e certamente potenciada por aquele desenvolvimento, uma forma de organização do poder político capaz de garantir a autonomia citadina, a Comuna. Este fenómeno contraria a tendência dominante que se registava além Alpes nos tempos da Baixa Idade Média, segundo a qual as entidades históricas de poder local, de dimensões relativamente reduzidas, se reorganizavam em estruturas territoriais mais vastas, globalizantes, mediante processos de unificação regional ou nacional.

A fisionomia político-civil da cidade comunal italiana delineia-se, assim, na sua capacidade para se constituir em Estado de facto (capacidade que partilha com algumas congéneres no espaço europeu), cuja autonomia decorre de um processo de consolidação crescente das prerrogativas públicas que as primeiras associações de cidadãos, num acto de 
reivindicação política e social, chamaram a si, aproveitando a debilidade do poder imperial-régio e a fragmentação, e consequente enfraquecimento, das autoridades locais ${ }^{3}$. No entanto, a sua singularidade advém sobretudo de uma evolução político-institucional que se consubstanciou em diversas etapas, por determinação de transformações políticas e sócio-económicas em acção no seio da comunidade urbana. $\mathrm{Na}$ verdade, como afirma Giorgio Chittolini, a cidade italiana "aveva mantenuto per almeno due secoli la capacità di porsi come libero luogo di incontro politico per ceti sociali vecchi e nuovi, di diversa origine e consistenza, in un gioco apertissimo, che aveva consentito a nuovi gruppi sociali, anche numericamenti crescenti, di contendere via via a ceti di forza e prestigio più antichi il controllo della vita cittadina; attraverso la creazione di quelle ben note istituzioni di una libera civiltà repubblicana $[\ldots]$ ". 4 .

Por confronto com o que por esse tempo se verifica no resto da Europa (com as excepções da Flandres e da Alemanha) e no próprio Mezzogiorno, poder-se-á dizer que as regiões Norte e Centro de Itália evoluiram para um avançado modelo estatal de base urbana, o governo a comune, favorável à participação directa de grande parte dos estratos sociais na gestão da res publica. Embora a Comuna na sua primeira fase tenha sido dominantemente aristocrática, bem cedo os grupos sócio-económicos donde provinham comerciantes, empreendedores financeiros e profissionais das leis conseguiram garantir o seu lugar no corpo administrativo da cidade.

Em linha de coerência com este quadro de fundo, emergiu uma nova cultura de fundamentos substancialmente laico-burgueses cujos operadores, juntamente com os seus concidadãos, partilhavam uma renascida consciência colectiva subjacente ao envolvimento empenhado na dinâmica da vida política. Ora, parece ter sido essa consciência colectiva, alimentada de espírito citadino, que moveu o interesse pela história da cidade e pelos acontecimentos públicos de memó- 
ria recente nela ocorridos. Com efeito, a historiografia urbana medieval, em Itália, acompanha o percurso temporal das autonomias urbanas e, aliás, algumas Comunas inauguraram-na a escassos anos de distância do seu próprio arranque institucional. Por isso já tem sido visto no discurso historiográfico que preserva a memória urbana, perfilada como vigário da autoconsciência colectiva, um meio para fornecer a justificação histórica ${ }^{5}$ daquelas novas formações políticas emergentes nos finais do séc. XI.

Corrobora esta ideia o facto de, em algumas cidades, a produção histórica ter sido fomentada pelas autoridades públicas. E também se deu o caso de obras historiográficas não solicitadas pelos organismos do poder acabarem por obter a consagração pública como custódia fidedigna da história urbana. Génova, talvez o exemplo mais ilustrativo, dispôs desde o séc. XII de uma historiografia institucionalizada ${ }^{6}$. Em Veneza, durante os séc. XIII e XIV, os textos que transmitiram a história da Serenissima beneficiaram de um carácter 'oficioso' e, mais, se dependentes de uma incumbência delegada nos seus autores, de um valor de 'oficialidade'7 uma crónica de Peruggia feita por Bonifacio Veronese, depois de lida em público perante as autoridades, e por elas aprovada, mereceu ser conservada junto da documentação da Comuna ${ }^{8}$.

Escrever a história da cidade significava então dar testemunho de uma identidade urbana na qual os membros da comunidade se reconheciam, moldando-lhes o orgulho cívico de facto patente em muitas páginas da historiografia produzida no seio das Comunas. Daí que seja corrente, no âmbito de uma concepção valorizadora do passado e, sobretudo, legitimadora do presente, o tema das origens da cidade remetidas não raro para um passado remoto, vizinho do mito e da lenda. Com este horizonte de antecedentes, e enquanto forma de exaltação da cidade, o tema das origens ou da fundação, filiando-se na tradição clássica da laus civitatis, podia 
estar ao serviço de um intuito propagandístico devedor da preocupação em caucionar a independência ou os direitos da Comuna e, ao mesmo tempo, em engrandecer o seu prestígio na actualidade garantido pela prerrogativa de uma atestada continuidade histórica.

Delimita-se deste modo, com contornos mais precisos, a ideia de história como crónica civil, ou seja, como discurso sobre e para os cidadãos, como protagonistas e destinatários. Logo, é a própria qualidade funcional e empreendedora do espaço humano, quadro social de relações integradoras, que justifica a necessidade da historiografia urbana. Parece ser este o grande denominador comum para a tipificação do paradigma narrativo citadino que, por outro lado, apresenta uma rica diversidade quando se percorre a geografia da sua produção. Considerando sobretudo os casos mais notáveis, respeitantes a Florença, Veneza e Génova, a diversificação do paradigma acompanha o perfil de cada um dos agregados, construído de acordo com as respectivas dinâmicas da vida político-institucional e tradição cultural.

No caso de Génova, onde a história urbana mereceu uma atenção precoce, registou-se, salvo um breve interregno, uma produção ininterrupta de anais desde a segunda metade do séc. XII até aos finais do seguinte. Uma prática contínua de analística com tal carácter de sistematicidade não é homologável à de nenhuma outra cidade.

Sobre as obras dos autores florentinos não se poderá dizer que tivessem conhecido um processo de oficialização equivalente àquele a que foram submetidos os anais de Caffaro, o iniciador da tradição dos Annales Iannuenses, nem sequer granjeado das autoridades municipais o crédito de um valor de oficialidade, como no caso das crónicas venezianas, acima anotado. Demonstra este facto que o tipo de relação estabelecido entre as classes no poder e a respectiva história urbana se deixava condicionar por ingredientes endógenos como, por exemplo, o reconhecimento, já antes referido, das van- 
tagens oferecidas pela obras historiográficas para fins políticos ou mesmo jurisdicionais ${ }^{9}$.

Os anais genoveses, na sua esmagadora maioria realizados pelos scribani publici ou cancellari da Comuna ${ }^{10}$, nomeados oficialmente para a função de porta-vozes fidedignos da história da República, mantiveram-se ciosamente guardados nos arquivos estatais como verdadeiros documentos, enquanto as crónicas florentinas, fruto de iniciativas privadas, nunca sofreram a reserva imposta à divulgação. Mas esta também não seria de grande alcance, atendendo a que a escolha linguística dos cronistas recaiu, aliás relativamente cedo em face da prática historiográfica de outras cidades, sobre o vernáculo de fala local ${ }^{11}$. Para sublinhar as diferenças, neste particular domínio da linguagem, vem a propósito invocar o exemplo da arreigada tradição veneziana de uma escrita em latim, apenas pontualmente infringida pela opção por uma língua que fosse capaz de assegurar uma mais ampla circulação à obra, como terá sucedido a Les estoires de Venise, de Martin da Canal.

No quadro de uma panorâmica mais lata, a aferição da não uniformidade das práticas historiográficas pode ser levada mais longe pela evidência das disparidades obtidas pelo cotejo dos seus tempos de génese e dos quantitativos de obras realizadas $^{12}$. Como acima se referiu, a história da cidade constituía um elemento de identidade colectiva específica dos diversos centros urbanos. Logo, cada uma das 'autobiografias' citadinas deveria espelhar o quadro de referências histórico-culturais que lhe servia de fundamento e legitimação. Quer isto dizer que os tempos diferenciados de génese, as modalidades de desenvolvimento, as condições de produção e as situações práticas da historiografia urbana são factores directamente condicionantes das respectivas escritas e, ao mesmo tempo, elementos de prova que podem ser invocados para atestar em favor do 'particularismo' tão característico da civilização comunal italiana. 
A variabilidade das realizações textuais do paradigma historiográfico urbano merece, por isso, ser tomada em especial consideração, no que respeita a evidentes diferenças de formas e de substâncias, com a ressalva da especificidade comum dos escritos da autoria dos notários-cronistas que, aliás, se contam em largo número entre os cultores da historiografia urbana. No geral marca-os a propensão para modelarem os seus textos pelo registo e estilo afeitos ao formulário documental ${ }^{13}$.

'Anais' e 'crónicas' foram os géneros mais cultivados mas, numa perspectiva global, em épocas distintas, pois a tendência predominante orientar-se-ia no sentido dos primeiros serem progressivamente preteridos pelas crónicas, género que se impôs entre os finais do séc. XIII e inícios do seguinte. Porém, em muitos casos houve certamente uma convergência ou mesmo confusão dos dois géneros. A Cronichetta lucchese, por exemplo, organiza-se essencialmente com base na sucessão das autoridades municipais e abusa com frequência da parataxe, duas feições típicas do registo analístico. Com a insistência na construção paractática, como se poderá observar no trecho abaixo citado, os factos e eventos, alinhados com evidente solução de continuidade, sucedem-se indiferenciados no que respeita ao relevo de importância de que uns poderiam usufruir sobre outros:

"1246. Fue potestade di Lucca domino Acerbo e fucci cacciato Ferrarino Cane di Papia; e fue lo fuoco di San Giovanni; et in quello anno la stimana di Santo Lucca, e lo popolo andò in Garfagnana per cagione che fue talliata la mano allo Iscariccio nostro cittadin di Lucca; e Lucca arse ville e castella e rocche; e questo fue perché lo Iscaricc[i]o regoe lo candaio alla Santa Croce $[\ldots]^{\prime \prime 14}$.

É de crer que o ponto de partida para a historiografia urbana tenha sido, com efeito, em várias cidades, as listagens de bispos ou de autoridades da Comuna que serviriam de 
base à constituição de anais, tendo a arquitectura diacrónica dos textos evoluído no sentido da passagem do esquema analístico à forma de encadeamento temporal apoiada numa estrutura narrativa, que parece atestar a progressiva importância alcançada pela continuidade (crono)lógica dos factos humanos.

A 'crónica', por seu turno, tornou-se com o correr do tempo, e de maneira notória no séc. XIV, cada vez menos sucinta no registo dos factos, contrariando assim, no seu percurso evolutivo, um dos traços definidores do género tal como o fixara Eusébio de Cesareia. De acordo com Bernard Guenée, o fenómeno da confluência entre a prioridade dada à narrativa e a prioridade dada à exactidão cronológica, características, respectivamente, da 'história' e da 'crónica' de formato eusebiano, começou a registar-se com um índice de frequência crescente nos últimos séculos do Ocidente medie$\mathrm{val}^{15}$. Afirma ainda este estudioso que os historiadores tenderam na sua prática "à créer une seule forme historique, mixte en quelque sorte, qui combinât l'exactitude de la chronique, en précisant les dates, et la beauté de l'histoire, en soignant le récit" ". No caso particular italiano, esta síntese de 'história' e de 'crónica' encontra-se bem representada na obra do florentino Giovanni Villani, a Nuova cronica.

Textos como La sconfitta di Monte Aperto ou a Cronica delle cose occorrenti ne' tempi suoi, de Dino Compagni, respondem antes por outro tipo genológico que adopta a designação de 'monografia histórica'. Quer na primeira, quer na segunda obras, os respectivos títulos restringem já os limites temporais que balizam o conteúdo narrado a um período muito breve. $\mathrm{O}$ autor senês procede à focalização de um único evento histórico, a batalha que teve lugar em 1260 e deu a vitória aos seus concidadãos sobre os florentinos. Compagni, que se centra essencialmente nos acontecimentos ocorridos em Florença entre 1280 e 1312, selecciona de preferência para o seu relato aqueles eventos respeitantes às vicissitudes das lutas que opuseram Bianchi e Neri. 
Se tomarmos como exemplos as obras dos dois autores florentinos até agora mencionados, Villani e Compagni, sobressai de imediato a grande disparidade entre textos em que o tempo humano narrável se cinge a uma perspectiva cronológica assaz restrita, a de um passado recente e muitas vezes contemporâneo do autor, e as narrativas que se estendem de um passado remoto (na Nuova cronica, a destruição da Torre de Babel), por influência certamente dos modelos da tradição da história 'ab orbe condito' até, também, ao tempo da actualidade da escrita. No caso ainda da crónica de Villani, o conteúdo narrado extrapola com frequência, como acontece em tantos outros textos da historiografia urbana, as fronteiras geográficas da cidade, recolhendo notícias de história geral, de âmbito 'nacional' e internacional. E, ao contrário da restritiva selecção tópica que Compagni opera no seu texto, o outro florentino partilha ainda o gosto comum entre os demais cronistas da época pelas anotações heteróclitas, de abertura enciclopédica, informativas sobre os mais diversos assuntos (milagres, prodígios, incêndios, dilúvios, cheias, eclipses, epidemias, etc.), que serão posteriormente banidas pela historiografia humanística, vocacionada em exclusivo para a história política.

Com a sua obra, cuja composição deve ter sido iniciada por volta do terceiro decénio do séc. XIV ${ }^{17}$, Villani apresenta uma nova maneira de conceber e escrever a crónica urbana, combinando a tradição e a convenção com elementos que poderemos reputar de inovadores face ao comum da prática historiográfica do seu tempo. Além do conhecido aspecto de ordem substancial relativo à extraordinária compilação de dados estatísticos sobre as rendas e despesas da Comuna, a população, a instrução, as magistraturas públicas, os edifícios públicos e, em especial, sobre as actividades produtoras de riqueza, comércio e manufacturas, que configuram uma problemática económica praticamente ignorada em outras crónicas medievais ${ }^{18}$ e ajudam a compor a 
imagem de uma Florença próspera e industriosa, dever-se-á igualmente destacar um conjunto de questões envolvendo os planos formal e semântico.

A ordenação do conteúdo narrado por cada um dos treze Livros que constituem a Nuova cronica complexifica o habitual esquema crono-histórico, seguindo determinados critérios de organização da matéria documental, cuja existência o autor-narrador faz questão em assinalar em alguns casos:

"E però cominceremo in raccontando quello diluvio il XII libro, però che ne pare che si convenga, però che fu quasi uno rimutamento di secolo della nostra città.”, XI, CCXXVII, vol. II, p. $798^{19}$.

"Conviene cominciare il XIII libro, però che richiede lo stile del nostro trattato; perch'è nuova materia, e grandi mutazioni e diverse rivoluzioni avennero in questi tempi alla nostra città di Firenze per le nostre discordie tra' cittadini, e male reggimento de' XX uficiali [...]”, XIII, I, vol. II, p. 291.

A tais critérios parece subjazer a concepção do percurso civilizacional segundo ciclos de evolução histórica que terão determinado o travejamento da arquitectura da crónica em "Livros" e "capítulos" delimitados, por norma, em função da importância atribuída a certos eventos na composição da história de Florença planificada pelo cronista. No cap. XXXVI do Liv. IX, depois de dar conta de que a ideia para a escrita da sua crónica lhe ocorreu quando, no decurso de uma peregrinação a Roma por ocasião do Jubileu do ano de 1300, contemplou "le grandi e antiche cose" da cidade e leu "le storie e' grandi fatti de'Romani" escritas pelos autores clássicos, acrescenta:

"Ma considerando che la nostra città di Firenze, figliuola e fattura di Roma, era nel suo montare e a seguire grandi cose, 
sì come Roma nel suo calare, mi parve convenevole di recare in questo volume e nuova cronica tutti i fatti e cominciamenti della città di Firenze [...]”, IX, XXXVI, vol. II, p. 58.

Para os concidadãos seus contemporâneos e vindouros, Villani projectou então escrever a história da trajectória ascensional da cidade desde as suas promissoras origens, embora, como observa Giuseppe Porta, "non è men chiaro che l'immagine di Firenze che egli vuole consegnare alla posterità si è modificata nel corso del tempo [...]"20. Na verdade, a imagem de "nobilità e grandezza della nostra città a' nostri presenti tempi” que, com indisfarçável orgulho cívico, exalta no "prologo", começa a ser "maculada', próximo do final da crónica, pelo acumular de factos e eventos de sinal negativo, reveladores de uma conjuntura de crise, ainda latente, indiciadora do declínio da prosperidade florentina.

Assim, abrirá vários Livros da sua crónica (II, III, IV, IX, XI, XII e XIII) narrando eventos cujo significado na história de Florença o destinatário não poderá deixar de reconhecer como cruciais, sejam eles "mutazioni averse" ou "filici” (I, I, vol. I, p. 3). Semelhante arrumação de conteúdos ganha ainda mais evidência quando o cronista decide concluir um Livro sem que tenha esgotado todos os factos que pretendia registar respeitantes a um determinado ano, transferindo um deles em particular para o começo do Livro seguinte. Cabe neste caso referir a emanação do corpus legislativo antimagnatizio, os "ordinamenti della giustizia", remetido para o início do Liv. IX. Notável também é o facto de, na redacção definitiva da crónica, o capítulo dedicado à edificação de Florença se separar do Liv. I para ir inaugurar o Liv. II, aumentando deste modo o número total de livros da Nuova cronica de XII para XIII ${ }^{21}$, por causa de uma vontade óbvia de pôr em destaque as gloriosas origens da "figliuola e fattura di Roma". 
Desta reordenação valorativa dos conteúdos narrativos se pode então inferir a ideia de trabalho criativo, de actividade autorial, distinta do gesto quase mecânico de quem regista factos avulsos. Um dos procedimentos que recuperam Villani do anonimato dos compiladores que o antecederam, consiste não por acaso no emprego de fórmulas como "io scritore" e "io autore" (ou "noi autore"), significantes da afirmação da ordem da escrita assumida como actividade produtiva. Confirmam um tal investimento os inúmeros trechos que utiliza para insistir na exigência em entrecruzar os eventos da sua cidade com os de história geral, a fim de produzir, de acordo com os objectivos expressos, uma reconstituição exacta da história florentina, pelo que o tradicional delineamento da chronica universalis, adoptado na obra, passa a receber novos sentidos e ganhos de coerência:

“[...] tornando poi a nostra materia e fatti della nostra città di Firenze, i quali per acrescimento e operazioni de'Fiorentini cominciò a moltiplicare e a istendere la fama di Firenze per l'universo mondo, più che non era stato per lo adietro; e imperciò quasi per necessità ne conviene nel nostro trattato [raccontare] più universalmente da quinci innanzi de' papi, e degl'imperadori, e de' re, e di più province del mondo le novità e cose state per gli tempi, imperciò che molto riferiscono alla nostra materia [...]", V, XVIII, vol. I, p. 190.

Como se verifica pelo excerto, o conteúdo textual, imediatamente importante num quadro de referências políticas de dimensão 'universal', por um lado, catapulta a cidade florentina, coroada de fama internacional, para uma situação de paridade com as grandes potências europeias e, por outro, assegura-lhe o estatuto de ponto de referência em virtude do qual as novidades 'de fora' são convocadas para o discurso. Aflui nítida a consciência que o cronista (com conhecimento de causa) detém e procura transmitir com 
alguma frequência ao leitor, quanto ao papel preponderante que a Florença do mundo das finanças e do grande tráfico detém no contexto europeu.

Evidentes são também no mesmo trecho os sinais do exercício de uma consciência organizativa que se preocupa em assegurar a coesão do narrado. No mesmo sentido podem ser lidos os breves enunciados que, segundo uma formulação discursiva tipificada, rematam muitos capítulos com a função de reger as articulações narrativas, como, por exemplo:

"Lasceremo de' fatti di Firenze, e torneremo alquanto a contare della guerra di Cicilia.", VIII, CXVI, vol. I, p. 580.

"Lasceremo alquanto della detta materia, e diremo d'altre novitadi di Firenze e di Toscana ne' detti tempi.”, I, CXVII, vol. I, 582.

Mediante a presença do autor-narrador que se oferece de uma maneira quase constante ao longo do texto, desvendando as suas 'técnicas' narrativas, parece que se explora um meio de afirmar o domínio seguro do mester de escritor da história. Na verdade, o cronista não descura nenhuma oportunidade para ostentar o seu empenho em controlar a extensão do relato, apresentando justificação para as fugas a um ideal de brevitas. E também se dá o caso de exibir o alcance do seu poder no que toca à selecção e triagem dos factos historiáveis:

"Avenne fatta menzione, non per lo detto Gianni, che non era degno di scrivere in cronica, ma per esemplo, e perché a' Fiorentini parve essere troppo fedeli del signore, per questa cagione recando in loro assempro che chi a uno offende a molti minaccia.", XI, XLVIII, vol. II, pp. 574-575.

A opção pelo "scrivere in cronica" um facto condenável do ponto de vista ético-civil, para o colocar ao serviço da 
pedagogia do exemplo pela negativa, deixa-se subscrever pela típica função morigeradora assumida pela obra. Com efeito, de tom análogo são os múltiplos excursos, sob a forma de comentários, em que Villani endereça ao destinatário uma advertência-exortação canalizada para a adopção de comportamentos aderentes à moral cristã. Vícios e pecados como a soberba, a inveja, a avareza, e sobretudo, a ingratidão no reconhecimento das benesses de Deus são invariavelmente apontados, no âmbito de uma concepção providencialista do devir humano, como penhor das atribulações dos florentinos decretadas pela sentença da Justiça Divina. O extenso excurso no capítulo dedicado à questão que ocupava os florentinos sobre as origens do dilúvio do ano de 1333 (XII, II) fornece a este propósito um dos melhores exemplos da crónica.

A concepção didáctica da história, por sua vez, torna-se também evidente nos comentários sobre conteúdos que fazem apelo à reflexão dos leitores, a fim de colherem nos factos do passado uma lição para o futuro, sobretudo quando está em causa o regimento da Comuna e, logo, o bem da República florentina, como no trecho seguinte:

"I nomi de' quali non ligisterremo in questo, però che non sono degni di memoria di loro virtù o buone operazioni per lo nostro Comune, ma del contrario, come inanzi per le loro operazioni si potrà vedere, acciò che' nostri successori si guardino di dare le sformate balìe a' nostri cittadini per lunghi tempi. Le quali per isperienza si manifesta per antico e per novello essere la morte e abassamento del nostro Comune [...]", XII, CXXX, vol. III, p. 250.

Por outro lado, e considerando ainda este último trecho, Villani dá mostras de uma atitude indagadora e interpretativa dos factos, legitimando assim a natureza dos comentários que endereça aos leitores, ensinamentos habilitados pela sua 
experiência de vida pública e pela capacidade de avaliação dos efeitos produzidos por determinadas causas. Se a isto associarmos a tentativa contínua de apurar os nexos que implicam logicamente os acontecimentos entre si ("le cagioni, e perché", de que fala no "Prólogo"), poder-se-á talvez dizer que a Nuova cronica enceta já a passagem da "história-relação" à "história-explicação"22. Retomando uma alusão anterior, dir-se-ia que Villani descobre e faz descobrir ao leitor a realidade da função de historiador. Ou, melhor ainda, a Nuova cronica veicula a emergência discursiva de uma consciência histórica.

Distintamente do que virá depois a ser o discurso da história, cuja objectividade aconselha a elisão da instância enunciadora, a Nuova cronica constitui um espaço onde a subjectividade do "eu" narrador expõe sem camuflagens a qualidade de autor com uma função nova em relação à do compilador. Enquanto a este se deve essencialmente a organização dos materiais, ao autor pertence não só a função de compilação mas também a função criativa que se exprime pela utilização e aplicação hermenêutica dos conteúdos documentais, responsável pelo que podemos designar por texto. Isto é, da conjunção entre os dados referenciais e a voz pessoal que lhes faz de contraponto valorativo resulta, nitidamente, o relacionamento projectivo entre o texto e as realidades historicamente situadas, e em perspectiva sobre o presente. Daí se deduzem entretanto as significações de valor ético, moral, social e cívico, finalmente exemplares de acordo com uma funcionalidade pedagógica que assim deve compreender não apenas os conteúdos referenciais da história mas ainda o seu sentido de exemplar morigeração.

Não existirão muitas crónicas do tempo da Itália comunal que abracem assim, de um modo tão empenhado e amadurecido como na obra de Villani, os requisitos do paradigma historiográfico assente na escrita da história de e para a cidade. Temporalmente, conota um contexto de época que baliza 
uma fase de transição entre a Idade Média e o Renascimento. Ainda medieval na sua concepção providencial da história e no gosto pelo enciclopedismo, é já também um anúncio do moderno quando se autodesigna de "autor" /" escritor" e exprime as suas opiniões convictas alicerçadas num saber feito de experiência empírica. Por isso Villani nos faz pressentir, embrionária, a afirmação humanística do indivíduo à espera de eclodir em Florença, cabeça de vanguarda do eminente movimento cultural.

\section{Notas e Bibliografia}

1. Cf. Jacques Le Goff, "História”, in Enciclopédia Einaudi, vol. I, Memória-História, Lisboa, Imprensa Nacional-Casa da Moeda, 1984, p. 191.

2. La sconfitta di Monte Aperto, in La prosa del Duecento, a cura di Cesare Segre e Mario Marti, Milano-Napoli, Riccardo Ricciardi, 1959, p. 941.

3. Cf. Lauro Martines, Potere e fantasia. La città stato nel Rinascimento, Roma-Bari, Laterza, 1981, p. 8 e sg..

4. Giorgio Chittolini, "Introduzione", in AA.VV., La crisi degli ordinamenti comunali e le origini dello stato del Rinascimento, a cura di G. Chittolini, Bologna, Il Mulino, 1996, p. 8.

5. Cf. Alfonso D'Agostino, "Itinerari e forme della prosa”, in Storia della letteratura italiana, diretta da Enrico Malato, Vol. I, Dalle Origini a Dante, Roma, Salerno, 1995, p. 550.

6. Cf. Girolamo Arnaldi, "Il notaio-cronista e le cronache cittadine in Italia", in La storia del diritto nel quadro delle scienze storiche, Atti del I Congresso internazionale della Società Italiana di Storia del Diritto, Firenze, Olschki, 1966.

7. Cf. Gina Fasoli, "Nascita di un mito", in AA.VV., Studi storici in onore di Gioacchino Volpe, Vol. I, Firenze, Sansoni, 1958; idem, "La Cronique des Veniciens di Martino da Canale", Studi medievali, serie III, fasc. I, Spoleto, 1951.

8. Cf. Marino Zabbia, "Notariato e memoria storica. Le scritture storiografiche notarili nelle città dell'Italia settentrionale (secc. XII-XIV), Bullettino dell'Istituto Storico Italiano per il Medio Evo e Archivio Muratoriano, n. 97, Roma, 1991.

9. Considere-se, por exemplo, o caso de Veneza. Cf., a este propósito, Antonio Carile, "Aspetti della cronachistica veneziana nei secoli XIII e XIV", in AA.VV., La storiografia veneziana fino al secolo XVI. Aspetti e problemi, a cura di Agostino Pertusi, Firenze, Olschki, 1970. 
10. Cf. Girolamo Arnaldi, "Cronache con documenti, cronache 'autentiche' e pubblica storiografia”, in AA.VV., Storici e storiografia del medioevo italiano, a cura di Gabriele Zanella, Bologna, Pàtron, 1984. pp. 127-128.

11. Para Laura Minervini, a opção de escrita dirigida a um público topograficamente mais disperso mas socialmente mais restrito é reveladora de que "la storiografia fiorentina appare perció fin dalla sua genesi più matura e conscia del suo ruolo, più immediata espressione delle ideologie etico-politiche del tempo". Cf. Laura Minervini, "La storiografia", in Manuale di letteratura italiana. Storia per generi e problemi, a cura di Franco Brioschi e Costanzo Di Girolamo, Vol. I, Dalle Origini alla fine del Quattrocento, Torino, Bollato Boringhieri, 1993, p. 774.

12. Vejam-se, a este propósito, as duas primeiras secções do estudo de Eric Cochrane intitulado Historians and Historiography in the Italian Renaissance, Chicago \& London, The University of Chicago Press, 1981.

13. Cf. Marino Zabbia, op. cit..

14. Cronichetta Lucchese, in La prosa del Duecento, a cura di Cesare Segre e Mario Marti, Milano-Napoli, Riccardo Ricciardi, 1959, p. 906.

15. Cf. Bernard Guenée, Histoire et culture historique dans l'Occident médiéval, Paris, Aubier, 1980, pp. 205-207.

16. Idem, ibidem.

17. Cf. Giuseppe Porta, "L'urgenza della memoria storica", in Storia della letteratura italiana, diretta da Enrico Malato, Vol. II, Il Trecento, Roma, Salerno, 1995, p. 175.

18. De acordo com Giovanni Aquilecchia, uma das novidades de Villani (um mercador e figura grada da classe dirigente de Florença) enquanto historiógrafo reside na "sistematica utilizzazione della propria esperienza professionale e politica" que responde pelo "prezioso bilancio dell'economia fiorentina per gli anni 1336-38" apresentado em vários capítulos do Liv. XI. Cf. Giovanni Aquilecchia, "Aspetti e motivi della prosa trecentesca minore", Schede di Italianistica, Torino, Einaudi, 1976, p. 8.

19. Esta e as restantes citações da obra reportam-se a Giovanni Villani, Nuova cronica, edizione critica a cura di Giuseppe Porta, 3 voll., Parma, Fondazione Pietro Bembo - Ugo Guanda Ed., 1990-1991.

20. Giuseppe Porta, op. cit., p. 176.

21. Cf. Giuseppe Porta, "Introduzione", in Giovanni Villani, Nuova cronica, edizione critica a cura di G. Porta, vol. I, Parma, Fondazione Pietro Bembo - Ugo Guanda Ed., 1990, pp. XII-XIII.

22. Conceitos utilizados por Olivier Soutet e Claude Thomasset a propósito das Mémoires de Commynes em "Des marques de la subjectivité dans les 'Mémoires' de Commynes", in La Chronique et l'Histoire au Moyen-Age, Colloque des 24 et 25 mai 1982, textes réunis par Daniel Poirion, Paris, Presses de l’Université de Paris-Sorbonne, 1986, p. 36. 